\title{
EFEITO DO CLORO NA ÁGUA DE LAVAGEM PARA DESINFECÇÃO DE ALFACE MINIMAMENTE PROCESSADA ${ }^{1}$
}

\author{
Shirley Aparecida Garcia BERBARI ${ }^{2, *}$, José Eduardo PASCHOALINO², Neliane F. Arruda SILVEIRA ${ }^{3}$
}

\begin{abstract}
RESUMO
Este trabalho de pesquisa foi desenvolvido com o objetivo de verificar a eficácia de diferentes concentrações de cloro utilizadas como agente sanitizante na água de lavagem de alface (Lactuca sativa L.), do tipo americana, minimamente processada. Na matériaprima foram realizadas contagens de bolores, leveduras e coliformes totais. No produto final foram realizadas contagens de bolores e leveduras, coliformes totais e avaliação sensorial. O processamento mínimo da alface compreendeu as seguintes etapas: corte do talo, desfolhamento da cabeça, primeira seleção, primeira lavagem, segunda seleção, corte em tiras, segunda lavagem, tratamento de imersão em soluções contendo 70,100 e $130 \mathrm{mg} / \mathrm{L}$ de cloro, centrifugação, acondicionamento em sacos plásticos e armazenamento a $2^{\circ} \mathrm{C}$ e a $20^{\circ} \mathrm{C}$. Os resultados mostraram que a imersão em solução contendo $70 \mathrm{mg} / \mathrm{L}$ de cloro confere a alface minimamente processada uma vida-útil de seis dias e em solução contendo 100 e $130 \mathrm{mg} / \mathrm{L}$, nove dias e que o seu aroma, textura e gosto não foram afetados por estes tratamentos.
\end{abstract}

Palavras-chave: alface; processamento mínimo; cloro.

\section{SUMMARY}

EFFECT OF CHLORINE IN THE WASHING WATER FOR DESINFECTION OF MINIMALLY PROCESSED LETTUCE. This research was carried out aiming at evaluating the efficacy of different concentrations of chlorine used as a sanitizer in the washing water of minimally processed lettuce (Lactuca sativa L.). Total coliform and mould and yeast counts were performed on the raw material. The same microbiological exams plus a sensory evaluation were performed on the final product. The minimal processing of the lettuce consisted of cutting, shredding, first selection of leaves, first washing, second selection, manual slicing, second washing, dipping in solutions of 70,100 and $130 \mathrm{mg} / \mathrm{L}$ of chlorine, spin drying, packaging in polyethylene bags and storage at $2^{\circ} \mathrm{C}$ and at $20^{\circ} \mathrm{C}$. The results showed that the chlorine solution containing $70 \mathrm{mg} / \mathrm{L}$ promoted a shelf-life of 6 days under refrigeration, and the 100 and $130 \mathrm{mg} / \mathrm{L}$ solutions, 9 days. The sensory characteristics such as texture and flavor were not affected by the treatments studied.

Keywords: lettuce; minimal processing; chlorine.

\section{1 - INTRODUÇÃO}

O mercado de produtos hortifrutícolas frescos tem crescido de maneira significativa nesta última década. O segmento desses produtos que mais cresce no mercado é o produto lavado, descascado, cortado ou fatiado, embalado cru e armazenado sob refrigeração, conhecido como 'minimamente processado', [2, 7, 9]. A popularidade de tais produtos vem principalmente da fa-

\footnotetext{
${ }_{1}^{1}$ Recebido para publicação em 28/12/00. Aceito para publicação em 18/05/01.

${ }^{2}$ Centro de Tecnologia de Hortifrutícolas do ITAL. Av. Brasil, 2880

C.P. 139. CEP 13073-001-Campinas-SP.

${ }^{3}$ Laboratório de Microbiologia do ITAL.

*A quem a correspondência deve ser enviada.
}

cilidade de preparo, exigida cada vez mais nos dias de hoje, uma vez que já vêm lavados, cortados e limpos, o que implica também na diminuição de geração de lixo doméstico [2].

Tradicionalmente, os produtos frescos não eram alvo de muita preocupação por parte de órgãos regulamentadores, pois eram considerados seguros, já que eram lavados e rapidamente consumidos no próprio local de preparo. Atualmente, com a tendência ao consumo das hortaliças minimamente processadas, a preocupação com riscos de natureza microbiológica, torna-se acentuada, pois muitas operações como corte, lavagem e embalagem são feitas manualmente, aumentando o risco de contaminações dos produtos.[5, 9]. Um fator que pode aumentar esse tipo de risco é que o corte das hortaliças libera os fluidos internos celulares e vasculares das mesmas, ricos em nutrientes, disponibilizando-os aos microrganismos, permitindo que estes se multipliquem e aumentem a carga microbiana inicial, [5]. Esse fato contribui sobremaneira para a redução da vida-deprateleira das hortaliças minimamente processadas, que por sua vez, são produtos prontos para o consumo e devem estar livres de patógenos, especialmente os de importância em saúde publica, cujas fontes potenciais podem estar no manipulador, dejetos de animais, pássaros, insetos e solo.

Muito se tem pesquisado em vários países com relação a contaminação de frutas e hortaliças, e surtos de toxinfecções alimentares associados a esses alimentos, que continuam a existir [3]. Entre as hortaliças mais vendidas para consumo cru está a alface (Lactuca sativa L), bastante utilizada na confecção de sanduíches, decorações de pratos, saladas, etc.,além do produto pronto para consumo, na forma de hortaliça minimamente processada, merecendo maiores atenções quanto ao aspecto da saúde pública. De acordo com FRANK e TAKEUSHI [6], hortaliças frescas, especialmente alface, têm sido identificadas como veículos significantes de patógenos relevantes em saúde pública, incluindo a bactéria entero-hemorrágica Escherichia coli O157:H7.

No Brasil, o conhecimento da poluição fecal de hortaliças, especialmente alfaces, data de 1945, quando alguns pesquisadores encontraram Escherichia coli em $29,3 \%$ de 252 amostras de diversas hortaliças pesquisadas. Em 1958, CHRISTÓVAO [4], demonstrou a existência desse problema em alfaces comercializadas no Estado de São Paulo. No final da década de 70 o problema já estava instalado, uma vez que estudos apontaram alta contaminação fecal em $54 \%$ das amostras de hortaliças analisadas, especialmente alfaces, coletadas no Estado de São Paulo [8]. Atualmente, produtos como tomates, alface, salsinha, couve e sucos de frutas como 
laranja e maçã, são as hortifrutículas mais incriminadas em surtos de toxinfecção alimentar em nível mundial, especialmente por terem sido incriminados como fonte de patógenos de significância em saúde pública como Escherichia coli O 157:H7, Salmonella sp., Listeria sp, e Shigella $s p$, bem como de agentes causais da hepatite A e parasitas [3].

A lavagem dos vegetais é a prática mais comum para se obter um produto mais seguro. É de primordial importância, no entanto, que essa água seja, antes de tudo, de boa qualidade. Se esse requisito não for atendido, a água passa a ser fonte de contaminação primária dentro da planta de processamento. A eficácia da operação de lavagem, entretanto, pode ser aumentada com a inclusão de antimicrobianos ou desinfetantes nessa água de lavagem. De acordo com BEUCHAT [3], o uso de soluções desinfetantes na água de lavagem de hortaliças minimamente processadas, reduz a contaminação e produtos microbiologicamente mais seguros podem ser obtidos. FRANK e TAKEUSHI [6], também afirmam que uma lavagem eficiente de hortaliças, em água adicionada de desinfetantes, é um ponto crítico de controle, utilizado com freqüência em países como os Estados Unidos da América do Norte. Segundo esses mesmos autores, essa operação tem a finalidade de reduzir a carga microbiana inicial, naturalmente presente nesse tipo de produto, e tem dado bons resultados práticos.

Algumas soluções antimicrobianas têm sido estudadas já há algum tempo, por pesquisadores da área de higiene de alimentos. Entre elas, pode-se citar as soluções desinfetantes a base de cloro, compostos de amônia quaternária, ácidos orgânicos, como o ácido cítrico, o acido láctico, entre outros. O cloro, em suas várias formas, especialmente na de sais de hipoclorito, é um dos sanitizantes empregados com mais sucesso nas indústrias de alimentos. São compostos eficientes e de baixo custo, tendo larga aplicação, como por exemplo na forma de spray, para o controle bacteriológico em indústrias de frutas e hortaliças [10].

Assim sendo, o presente trabalho teve como objetivo verificar a eficácia de diferentes concentrações de cloro utilizadas como agente sanitizante na água de lavagem de alface, do tipo americana, minimamente processada.

\section{2 - MATERIAL E MÉTODOS}

\section{1 - Matéria-prima}

A matéria-prima, alface americana in natura foi obtida em varejões do comércio local de Campinas - SP. O lote de matéria-prima foi transportado ao laboratório em caixas plásticas, sem refrigeração. Os processamentos foram realizados nos mesmos dias em que a alface havia sido colhida.

\section{2 - Processamento}

As operações utilizadas no processamento da alface estão apresentadas no fluxograma constante da Figura 1.

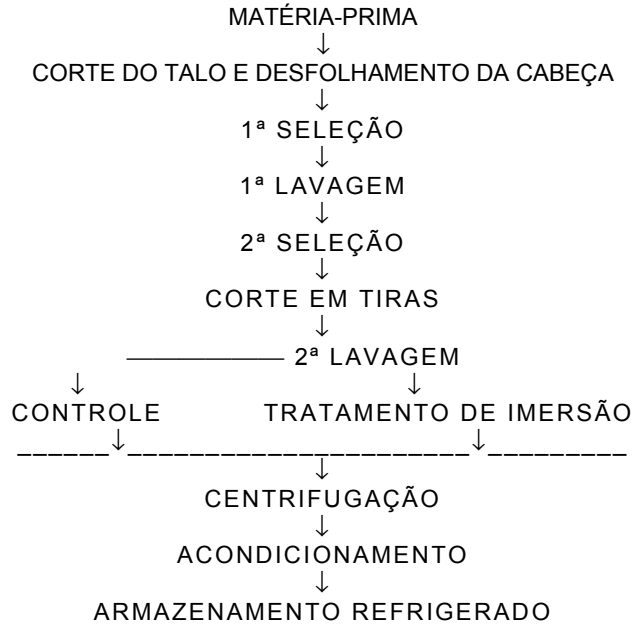

FIGURA 1. Fluxograma das etapas de processamento de alface minimamente processada.

O corte do talo e o desfolhamento da cabeça foram realizados manualmente, com o auxílio de facas inoxidáveis de lâmina fina. Na primeira seleção foram descartadas as folhas externas e as internas que apresentavam qualquer tipo de danos. A primeira lavagem foi realizada através da imersão das folhas em cuba de aço inoxidável contendo água tratada (rede urbana) e agitada manualmente. Na segunda seleção foram retiradas as folhas com danos que não foram detectadas na seleção anterior. O corte em tiras foi efetuado manualmente com o auxílio de facas inoxidáveis de lâmina fina. A segunda lavagem foi realizada em bandejas de aço inoxidável e teve por finalidade remover o fluído celular e vascular presentes nas extremidades cortadas da tiras de folhas, ricos em nutrientes e que auxiliam a multiplicação da carga microbiana inicial. A amostra controle foi submetida apenas às operações de lavagem com água da rede. As demais amostras foram submetidas a tratamentos de imersão em água clorada com 70, 100 e 130mg/L de cloro por 15 minutos, na proporção de $2 \mathrm{~kg}$ de alface para $20 \mathrm{~L}$ de solução. Após a desinfecção, para a retirada da água da superfície, a alface foi centrifugada por 2 minutos. O acondicionamento foi realizado em sacos de polietileno contendo $120 \mathrm{~g}$ de produto. O armazenamento das amostras foi efetuado a temperatura de $2^{\circ} \mathrm{C}$ e de $20^{\circ} \mathrm{C}$.

\section{3 - Análises microbiológicas}

Foi avaliada a eficácia antimicrobiana de diferentes concentrações de cloro, conforme descrito no item 2.2, contra a microbiota contaminante: bactérias do grupo coliformes totais e bolores e leveduras. A metodologia utilizada está contida em VANDERZANT \& SPLITTSTOESSER [13].

As análises microbiológicas foram realizadas no dia do processamento e após três e oito dias de armazenamento a $2^{\circ} \mathrm{C}$ e a $20^{\circ} \mathrm{C}$. De acordo com a metodologia citada, $25 \mathrm{~g}$ das amostras foram pesadas em $225 \mathrm{~mL}$ do 
diluente, água salina peptonada 0,1\%, e homogeneizadas em homogeneizador de pistão tipo Stromacher Blender 400. A seguir, foram diluídas em série e semeadas em meios específicos para cada exame, sendo utilizado o DRBC (Dicloran-rosa-de-bengala clorofenicol), para bolores e leveduras e o Petrifilm (3M) coliformes totais para a pesquisa de bactérias do grupo coliformes totais. As contagens foram feitas após 3 a 5 dias de incubação a $25^{\circ} \mathrm{C}$ para bolores e leveduras e após 24 horas a $35^{\circ} \mathrm{C}$ para os coliformes totais. Os resultados foram expressos em logarítmico das unidades formadoras de colônias por grama de alface(LogUFC/g).

\section{4 - Análise sensorial}

As amostras em estudo foram avaliadas subjetivamente quanto à aparência, aroma, textura e gosto. Os testes foram realizados por uma equipe de 15 provadores, com periodicidade de 3 dias, em amostras armazenadas a $2^{\circ} \mathrm{C}$, por nove dias. No terceiro dia de armazenamento a $20^{\circ} \mathrm{C}$, as amostras não se apresentaram adequadas ao consumo, não apresentando condições de serem submetidas a avaliação sensorial. Foram utilizadas escalas horizontais, não estruturadas e com $9 \mathrm{~cm}$ de comprimento. As amostras foram servidas aos provadores em pratos plásticos brancos contendo aproximadamente $30 \mathrm{~g}$ de alface. Os valores obtidos foram avaliados estatisticamente através de análise de variância(Teste $F$ ) e diferença entre as médias(Teste de Tukey), conforme procedimentos descritos por MORI et al [12].

\section{3 - RESULTADOS E DISCUSSÃO}

\section{1 - Análises microbiológicas}

Os resultados obtidos na avaliação da alface americana minimamente processada estão contidos na Tabela 1.

TABELA 1. Contagem de bolores, leveduras e coliformes totais em alfaces minimamente processadas e submetidas a diferentes tratamentos de imersão em água clorada e armazenadas a $2^{\circ} \mathrm{C}$.

\begin{tabular}{ccccccccc}
\hline & \multicolumn{6}{c}{ Tempo de armazenamento(dias) } \\
\cline { 2 - 9 } & \multicolumn{3}{c}{ Bolores e leveduras } & \multicolumn{5}{c}{ Coliformes totais } \\
\hline TRATAMENTOS & 0 & 3 & 6 & 9 & 0 & 3 & 6 & 9 \\
\hline In natura & $1.0 \times 10^{4}$ & $2.4 \times 10^{4}$ & $3.6 \times 10^{5}$ & - & $6.6 \times 10^{5}$ & $6.8 \times 10^{5}$ & $6.9 \times 10^{6}$ & - \\
Controle & $2.0 \times 10^{3}$ & $2.0 \times 10^{3}$ & $4.6 \times 10^{3}$ & $1.4 \times 10^{6}$ & $4.2 \times 10^{3}$ & $4.3 \times 10^{3}$ & $1.0 \times 10^{5}$ & $2.3 \times 10^{8}$ \\
$70 \mathrm{mg} / \mathrm{L} \mathrm{Cl}$ & $8.0 \times 10^{2}$ & $9.3 \times 10^{2}$ & $8.7 \times 10^{3}$ & $5.1 \times 10^{5}$ & $4.2 \times 10^{3}$ & $5.1 \times 10^{4}$ & $6.4 \times 10^{4}$ & $6.9 \times 10^{6}$ \\
$100 \mathrm{mg} / \mathrm{L} \mathrm{Cl}$ & $<10^{2}$ & $5.0 \times 10^{2}$ & $6.3 \times 10^{2}$ & $6.1 \times 10^{3}$ & $1.5 \times 10^{2}$ & $5.0 \times 10^{2}$ & $9.8 \times 10^{2}$ & $2.0 \times 10^{4}$ \\
$130 \mathrm{mg} / \mathrm{L} \mathrm{Cl}$ & $<10^{2}$ & $4.0 \times 10^{2}$ & $5.0 \times 10^{2}$ & $3.1 \times 10^{3}$ & $7.7 \times 10^{1}$ & $1.2 \times 10^{2}$ & $5.0 \times 10^{2}$ & $1.6 \times 10^{4}$ \\
\hline
\end{tabular}

* UFC/g= Unidades Formadoras de Colônias - Média de duas repetições

Conforme pode ser observado na Tabela 1, a matéria-prima utilizada mostrou elevada contaminação inicial por coliformes totais, bolores e leveduras, uma vez que no geral, populações no nível de $10^{5}$ UFC por grama de coliformes totais e de $10^{4} \mathrm{UFC} / \mathrm{g}$ de bolores e leveduras foram encontradas nas alfaces sem lavagem alguma. Quando a operação de lavagem com a água de rede foi efetuada, uma redução inicial de 2 ciclos logarítmicos na contagem de coliformes totais e de um ciclo logarítmico na contagem de bolores e leveduras, pode ser observada. Segundo LEITÃO et al [11], quando se pesquisa eficiência de um agente germicida, em indústria de alimentos, deve se considerar também que a redução observada nas contagens microbianas, não devem ser atribuídas exclusivamente à atividade germicida do agente desinfetante, tendo que considerar que o efeito pode estar conjugado a uma remoção das células na lavagem inicial, em água de boa qualidade. Esse dado encontrado na presente pesquisa, está de acordo com aqueles já relatados por outros autores, que há duas décadas atrás, encontraram populações em níveis semelhantes de bactérias do grupo coliformes em hortaliças cultivadas no Estado de São Paulo [8]. Esse fato reforça a necessidade da observação das boas práticas de manufatura nas operações do processamento mínimo de hortaliças, especialmente daquelas que serão consumidas cruas, visando a obtenção de um produto mais seguro do ponto de vista de saúde pública. Para o tratamento de imersão em solução contendo 70mg/ $\mathrm{L}$ de cloro, observou-se uma redução inicial de 2 ciclos logarítmicos para as contagens de bolores, leveduras e de coliformes totais, que se manteve até o terceiro dia de armazenamento refrigerado. Ao nono dia de armazenamento, verificou-se uma alteração de três ciclos logarítmicos da carga microbiana inicial, ou seja uma contagem de $10^{5} \mathrm{UFC} / \mathrm{g}$ de bolores e leveduras e $10^{6} \mathrm{UFC} / \mathrm{g}$ de coliformes totais, o que significa uma contagem alta e o término da vida-útil do produto. Os tratamentos de imersão em soluções contendo 100 e 130mg/ $L$ de cloro mostraram eficiência na redução das populações microbianas estudadas muito semelhante, os quais reduziram a carga microbiana inicial de coliformes totais de três ciclos logarítmicos e de bolores e leveduras de dois ciclos logarítmicos, o que foi observado até o sexto dia de armazenamento refrigerado. No final do período de armazenamento, a população de bolores e leveduras encontrada foi de $10^{3} \mathrm{UFC} / \mathrm{g}$ e de $10^{4} \mathrm{UFC} / \mathrm{g}$ para coliformes totais, que são níveis considerados razoavelmente altos, embora, aparentemente a alface se encontrasse ainda em boas condições, isto é, sem alterações visíveis. A Legislação Brasileira, ANVISA - Resolução RDC-12 [1], indica como padrão microbiológico para hortaliças, legumes e similares - frescas, in natura, preparadas (descascadas ou selecionadas ou fracionadas), sanificadas, refrigeradas ou congeladas para consumo a contagem de $10^{2}$ UFC de coliformes fecais por grama de produto. Segundo GOPAL [9], a concentração de $100 \mathrm{mg} / \mathrm{L}$ de cloro é a mais utilizada em indústrias de alimentos em países como a Austrália e Nova Zelândia.

Em temperatura de abuso $\left(20^{\circ} \mathrm{C}\right)$, ao terceiro dia de armazenamento, todas as amostras de alface submetidas aos tratamentos de imersão em soluções contendo 70, 100 e 130mg/L de cloro apresentavam aparência deteriorada e contagens de coliformes totais e bolores e leveduras altas, ou seja, maiores que $10^{5} \mathrm{UFC} / \mathrm{g}$. 


\section{2 - Análise Sensorial}

A Tabela 2 mostra os resultados obtidos pela avaliação sensorial da alface minimamente processada, submetida a diferentes tratamentos de imersão em cloro. Observando estes resultados, pode-se verificar que os tratamentos estudados não provocaram diferença entre as amostras no que diz respeito ao aroma, textura e gosto, durante as três diferentes datas de avaliação. De acordo com a escala utilizada e com as médias recebidas pelas amostras, o aroma e o gosto foram considerados característicos e a textura crocante. Entre as características sensoriais avaliadas, somente para a aparência - cor, foi verificada diferença significativa, em todas as datas avaliadas. Porém, como esta avaliação foi realizada apenas em termos de coloração verde, estes resultados podem representar apenas a variação característica de tons verde que toda hortaliça apresenta e não propriamente o efeito dos tratamentos.

TABELA 2. Atributos sensoriais da alface minimamente processada.

\begin{tabular}{|c|c|c|c|c|c|}
\hline \multicolumn{6}{|c|}{$1^{\circ}$ Data de avaliação(3 dias) } \\
\hline & \multicolumn{5}{|c|}{ Média dos Tratamentos } \\
\hline Atributos & $70 \mathrm{mg} / \mathrm{L}$ & $100 \mathrm{mg} / \mathrm{L}$ & $130 \mathrm{mg} / \mathrm{L}$ & Controle & $\mathrm{F}$ \\
\hline Aparência-Cor & $2.40^{\mathrm{b}}$ & $3.80^{\mathrm{a}}$ & $2.70^{\mathrm{b}}$ & $1.35^{\mathrm{c}}$ & $8.26^{*}$ \\
\hline Aroma & 5.45 & 5.20 & 5.80 & 5.40 & $1.11^{\text {n.s. }}$ \\
\hline Textura & 6.30 & 5.40 & 5.50 & 5.10 & $0.23^{\text {n.s. }}$ \\
\hline Gosto & 6.15 & 5.90 & 6.20 & 5.90 & $0.22^{\text {n.s. }}$ \\
\hline \multicolumn{6}{|c|}{$2^{\circ}$ Data de avaliação(6 dias) } \\
\hline & \multicolumn{5}{|c|}{ Média dos Tratamentos } \\
\hline Atributos & $70 \mathrm{mg} / \mathrm{L}$ & $100 \mathrm{mg} / \mathrm{L}$ & $130 \mathrm{mg} / \mathrm{L}$ & Controle & $\mathrm{F}$ \\
\hline Aparência-Cor & $2.40^{\mathrm{b}}$ & $4.70^{\mathrm{a}}$ & $2.30^{\mathrm{b}}$ & $3.90^{\mathrm{a}}$ & $21.44^{*}$ \\
\hline Aroma & 5.95 & 4.90 & 4.90 & 5.70 & $1.82^{\text {n.s. }}$ \\
\hline Textura & 5.10 & 5.20 & 5.20 & - & $0.15^{\text {n.s. }}$ \\
\hline Gosto & 5.10 & 4.00 & 5.00 & - & $1.99^{\text {n.s. }}$ \\
\hline \multicolumn{6}{|c|}{$3^{\circ}$ Data de avaliação(9 dias) } \\
\hline & \multicolumn{5}{|c|}{ Média dos Tratamentos } \\
\hline Atributos & $70 \mathrm{mg} / \mathrm{L}$ & $100 \mathrm{mg} / \mathrm{L}$ & $130 \mathrm{mg} / \mathrm{L}$ & Controle & $\mathrm{F}$ \\
\hline Aparência-Cor & $3.25^{\mathrm{b}}$ & $5.35^{\mathrm{a}}$ & $2.60^{\mathrm{b}}$ & $1.40^{\mathrm{C}}$ & $35.52^{*}$ \\
\hline Aroma & 4.90 & 5.17 & 5.70 & 4.90 & $1.02^{\text {n.s. }}$ \\
\hline Textura & 5.60 & 5.30 & 5.00 & - & $1.10^{\text {n.s. }}$ \\
\hline Gosto & 5.80 & 5.50 & 5.20 & - & $0.25^{\text {n.s. }}$ \\
\hline
\end{tabular}

*Significativo ao nível de $0,5 \%$ de probabilidade

Médias seguidas das mesmas letras não diferem significativamente entre si.

\section{4 - CONCLUSÕES}

Os resultados encontrados no presente trabalho, levam as seguintes conclusões:

- a matéria-prima utilizada mostrou elevada contaminação microbiana, especialmente por bactérias do grupo coliformes totais, enfatizando a necessidade da observação das boas práticas de manufatura quando se tratar de produtos minimamente processados;
- $\quad$ tomando como base, que níveis populacionais maiores que $10^{5} \mathrm{UFC} / \mathrm{g}$ já são indicadores de final de vida-útil, pode-se concluir que, sob refrigeração $\left(2^{\circ} \mathrm{C}\right)$, a durabilidade da alface foi de seis dias para o tratamento com $70 \mathrm{mg} / \mathrm{L}$ de cloro e de nove dias para o tratamentos com 100 e 130mg/L de cloro;

- as concentrações de cloro estudadas não afetaram o aroma, a textura ou o gosto da alface.

\section{5 - REFERÊNCIAS BIBLIOGRÁFICAS}

[1] AGÊNCIA NACIONAL DE VIGILÂNCIA SANITÁRIA - ANVISA. Resolução RDC -12 de 2 de janeiro de 2001 - D.O.U. de 10/01/2001.

[2] BARRIGA,M.I.; G. TRACH; C. WILLEMOT; and R.E. SIMARD. Microbial changes in shedded iceberg lettuce stored under controlled atmospheres. Journal of Food Science,v. 56 n. 6, p. 47-58,1991.

[3] BEUCHAT, L.R. Standardization of methods to determine the efficacy of desinfectants for raw fruits and vegetables. In: TUIJTELAARS, et al, (eds) Food Microbiology and Food safety into the next millenium. Proceedings of 17 th International Conference of International Committee on Food Microbiology and Hygiene (ICFMH), Vendhoven, The Netherlands, 13-17, September,1999, p. 785-786, 1999.

[4] CHRISTÓVAO, D.A. Contaminação da alface (Lactuca sativa L) por microrganismos de origem fecal. São Paulo, 1958. Tese para catedrático de Microbiologia e Imunologia Aplicada da Faculdade de Higiene e Saúde Pública da Universidade de São Paulo (USP).

[5] FARBER, J. Microbiological issues surrounding the safety of fresh cut produce. 10th, World Congress of Food Science and Technology. Abstract Book, Sydney, Australia; p.11, 1999.

[6] FRANK,J.F.; K. TAKEUSHI.. Direct observation of Escherichia coli O157:H7 inactivation on lettuce leaf using confocal scanning laser microscopy. In: TUIJTELAARS, et al, (eds) Food Microbiology and Food safety into the next millenium. Proceedings of 17 th International Conference of International Committee on Food Microbiology and Hygiene (ICFMH), Vendhoven, The Netherlands, 13-17, September, p. 795-797, 1999.

[7] GARG, N.; J.J. CHUREY, and D.F. SPLITISTOESSER. Effect of processing conditions on the microflora of fresh cut vegetables. Journal of Food Protection, v. 53, n. 8, p. 701-703, 1990.

[8] GELLI, D.S.; T. TACHIBANA; I.R. OLIVEIRA; C.Q.ZAMBONI; J.A.PACHECO; e N. SPITERI. Condições higienico-sanitárias de hortaliças comercializadas no Estado de São Paulo,Sp, Brasil. Revista do Instituto Adolfo Lutz, v. 39, p. 37-43, 1979.

[9] GOPAL, A.; S. AJLONNI; H. ROGINSKIF; J. COVENTRY and J. WAN. Application of non-conventional desinfection techniques to extend the shelf-life of minimally processed foods. 10th, World Congress of Food Science and Technology. Abstract Book, Sydney, Australia, 1999.

[10] KIM, J.G.; YOUSEF, E. and DAVE, S. Application of ozone for enhancing the microbiological safety and quality of foods: a review. Journal of Food Protection, v. 62, n. 9, p. 10711087, 1999.

[11] LEITÃO, M.F.F; E. MONTEIRO FILHO; I. DELAZARI and E. ANGELUCCl, Effects of chemical desinfectants for reducing 
bacterial contamination in lettuce (Lactuca sativa $L$ ). Boletim do Instituto de Tecnologia de Alimentos, Campinas, Brasil, v. 19, p. 201-226,1981.

[12] MORI, E.E.M. et al. Métodos sensoriais e físicos para avaliação de alimentos e bebidas: princípios de aplicação. Campinas: ITAL, 1982. 177p. (Apostila).
[13] VANDERZANT, C., SPLITTSTOESSER, D.F. Compendium of methods for the Microbiological Examination of Foods, 3.ed. Washington: Americam Public Health Association, 1992, 1219p. 